\title{
Corticosteroid phobia: a questionnaire study using TOPICOP score
}

\author{
Ellie $\underline{\text { Choi }}^{1}$, MBBS, MMed, Nisha Suyien $\underline{\text { Chandran }}{ }^{1}$, MBBS, MMed, Chris $\underline{\text { Tan }^{1}}$, MBBS, FAMS
}

INTRODUCTION Topical corticosteroids (TCS) are commonly used in dermatology for their anti-inflammatory action. The recent development of the TOPICOP@ (Topical Corticosteroid Phobia) scale to assess steroid phobia has made the quantification and comparison of steroid phobia easier. The objective of this study was to assess the degree of steroid phobia at our institute and identify sources from which patients obtain information regarding TCS.

METHODS A cross-sectional survey was performed of dermatology patients regardless of steroid use. TOPICOP scale was used for the survey. Sources from which patients obtained information were identified and their level of trust in these sources assessed.

RESULTS 186 surveys were analysed. The median domain TOPICOP subscores were $38.9 \%$ (interquartile range [IQR] $27.8 \%-50.0 \%$, standard deviation [SD] 24.4\%) for knowledge and beliefs, 44.4\% (IQR 33.3\%-66.7\%, SD 24.4\%) for fears and 55.6\% (IQR 33.3\%-66.7\%, SD 27.2\%) for behaviour. The median global TOPICOP score was $44.4 \%$ (IQR 33.3\%-55.6\%, SD 17.6\%). Female gender was associated with higher behaviour, fear and global TOPICOP scores. There was no difference in the scores based on disease condition, steroid use, age or education. Dermatologists were the most common source of information on topical steroids and trust was highest in dermatologists.

CONCLUSION The prevalence of steroid phobia in our dermatology outpatient setting was moderately high, with gender differences. Dermatologists were the most common source of information on TCS, and it was heartening to note that trust was also highest in dermatologists. Strategies to target steroid phobia should take into account these factors.

Keywords: steroid phobia, topical corticosteroid concern, topical corticosteroids, TOPICOP scale

\section{INTRODUCTION}

Topical corticosteroids (TCS) are commonly prescribed in the dermatological setting for their anti-inflammatory properties for ailments ranging from inflammatory diseases to autoimmune disorders.

While it is known that TCS are safe in the long term when used appropriately, ${ }^{(1)}$ fear of side effects of TCS (TCS phobia) remains prevalent among patients. A systematic review of 16 studies in 2017 reported the prevalence of TCS phobia in the range of $21.0 \%-83.7 \%{ }^{(2)}$ TCS phobia has also been found to result in higher treatment non-compliance. ${ }^{(2)}$ The recent development of the TOPICOPC (Topical Corticosteroid Phobia) scale $\mathrm{e}^{(3,4)}$ to assess steroid phobia in patients with atopic dermatitis and their caregivers has made the quantification and comparison of steroid phobia easier. It was also recently used to assess steroid phobia associated with psoriasis. ${ }^{(5)}$

Steroid phobia may be partly attributed to the excessive or exaggerated risks depicted by the Internet, family/friends and even medical professionals. A study by Smith et $\mathrm{al}^{\left({ }^{(6)}\right.}$ reported that a third of survey participants received misinformation in the form of exaggerated risks from friends/family and over the Internet. Research by the same group also found that $76 \%$ of participants reported consistently receiving messages regarding TCS risk from general practitioners or pharmacists. ${ }^{(7,8)}$

Patients and parents who are steroid-phobic may seek complementary and alternative treatment with traditional Chinese medicines, ${ }^{(9)}$ which are believed to be safer non-steroidal alternatives. These may, however, also contain steroids and lead to unintentional liberal use of potent topical steroids. ${ }^{(10)}$

The aim of this study was to evaluate the phenomenon of TCS phobia in a broad group of dermatological patients regardless of disease condition or steroid use. We also explored their sources of information on TCS.

\section{METHODS}

A cross-sectional survey was designed to assess perceptions towards TCS in a broad group of patients regardless of steroid usage. The survey was self-administered in English. We recruited patients seen at the outpatient dermatology clinics at the National University Hospital, Singapore, regardless of dermatological diagnosis or usage of TCS. Patients or their caregivers were invited to complete the survey. Those who were unable to read English or were unfamiliar with TCS were excluded. The study was approved by the hospital research ethics committee.

The questionnaire was divided into four parts. The first part comprised the TOPICOP score. It consisted of 12 items assessing three domains of TCS phobia, knowledge and beliefs, fears and behaviour. Responses were graded on a four-point Likert scale (score range 0-3: $0=$ never, $1=$ sometimes, $2=$ often and 3 = always; or $0=$ totally disagree, $1=$ do not really agree, 2 = almost agree and $3=$ totally agree) to a maximum of 36 points.

We also added three questions that assessed fear of steroid addiction, usage of traditional Chinese medications/herbal

${ }_{1}^{1}$ Division of Dermatology, Department of Medicine, National University Healthcare System, Singapore

Correspondence: Dr Ellie Choi, Resident, Division of Dermatology, Department of Medicine, National University Hospital, National University Healthcare System, 5 Lower Kent Ridge Road, Singapore 119074. ellie_choi@nuhs.edu.sg 
medications and the willingness to use a more expensive non-steroidal agent.

The second part of the questionnaire surveyed sources of information from which patients obtained information regarding TCS and assessed their level of trust in these different sources. The third part of the questionnaire included patient demographics, dermatological condition and previous prescription of TCS. In the last part of the questionnaire, patients who had been prescribed topical steroids were additionally asked to comment on whether they had benefitted from their use and if they had experienced side effects.

Proportions were calculated excluding missing values. Global TOPICOP score and domain subscores for each participant were calculated as a percentage of the sum of all answered questions, resulting in a score in the range of $0 \%-100 \%$. Responses were analysed using descriptive statistics.

Mann-Whitney $U$ test was used to identify binary variables associated with greater TOPICOP scores, while the KruskalWallis test was used to identify variables with multiple groups associated with greater TOPICOP score. Univariate linear regression analysis was used to investigate factors associated with increased TCS phobia. Statistical analysis was performed using IBM SPSS Statistics version 21.0 (IBM Corp, Armonk, NY, USA). A p-value $<0.05$ was considered to be statistically significant.

\section{RESULTS}

190 surveys were collected between September 2017 and November 2017, of which four were excluded due to multiple incomplete questions. The remaining 186 surveys were analysed.

Demographics and clinical characteristics are shown in Table I. Among the participants, 42.5\% were men and 57.5\% were women. Median age of participants was 36 (interquartile range [IQR] 24-52) years. The top two most common skin conditions were eczema (53.6\%) and psoriasis (10.2\%). $161(86.6 \%)$ participants had previous or current use of TCS.

The percentages of responses to the questionnaire are shown in Table II. These were categorised by the dimensions assessed in the TOPICOP score, as well as using the additional questions we included that are relevant to our local context.

The median domain subscores were 38.9\% (IQR 27.8\%$50.0 \%$, standard deviation [SD] 24.4\%) for knowledge and beliefs, $44.4 \%$ (IQR 33.3\%-66.7\%, SD 24.4\%) for fears and 55.6\% (IQR $33.3 \%-66.7 \%$, SD $27.2 \%)$ for behaviour. The median global TOPICOP score was $44.4 \%$ (IQR $33.3 \%-55.6 \%$, SD $17.6 \%$ ).

There were no significant differences in individual subscores or global TOPICOP score when respondents were stratified according to disease condition (e.g. eczema or non-eczema, psoriasis or non-psoriasis) or exposure to TCS. Similarly, there was no difference when respondents were stratified by ethnicity, highest education level or employment status.

Compared to men, women were found to have higher mean scores for behaviour (women $56.7 \%$, men $42.8 \%$; $p=0.001$ ), fear (women $53.0 \%$, men $40.7 \% ; p=0.0004$ ) and global TOPICOP score (women $46.7 \%$, men $39.4 \% ; p=0.007$ ). There was no
Table I. Demographics and clinical characteristics of participants.

\begin{tabular}{|c|c|}
\hline Variable & No. (\%) \\
\hline \multicolumn{2}{|l|}{ Gender $(n=181)$} \\
\hline Male & $77(42.5)$ \\
\hline Female & $104(57.5)$ \\
\hline \multicolumn{2}{|l|}{ Age range (yr; $n=166$ ) } \\
\hline$\leq 20$ & $15(9.0)$ \\
\hline $21-30$ & $52(31.3)$ \\
\hline $31-40$ & $27(16.2)$ \\
\hline $41-50$ & $30(18.1)$ \\
\hline $51-60$ & $23(13.9)$ \\
\hline$\geq 61$ & $19(11.4)$ \\
\hline \multicolumn{2}{|l|}{ Ethnicity $(n=183)$} \\
\hline Chinese & $134(73.2)$ \\
\hline Malay & $23(12.6)$ \\
\hline Indian & $19(10.4)$ \\
\hline Caucasian & $6(3.3)$ \\
\hline Other & $1(0.5)$ \\
\hline \multicolumn{2}{|l|}{ Education $(n=178)$} \\
\hline Primary school & $9(5.1)$ \\
\hline Secondary school & $23(12.9)$ \\
\hline Junior college/polytechnic/ITE & $67(37.6)$ \\
\hline Bachelor's degree & $52(29.2)$ \\
\hline Master's degree or doctorate & $27(15.2)$ \\
\hline \multicolumn{2}{|c|}{ Top 6 reported skin conditions* $(n=166)$} \\
\hline Eczema & 89 \\
\hline Psoriasis & 17 \\
\hline Urticaria & 16 \\
\hline Acne & 12 \\
\hline Pigmentation & 8 \\
\hline Infection & 8 \\
\hline \multicolumn{2}{|l|}{ Period of steroid use $(n=159)$} \\
\hline$<2$ wk & $59(37.1)$ \\
\hline 2 wk-3 mth & $42(26.4)$ \\
\hline $3 \mathrm{mth}-1 \mathrm{yr}$ & $19(11.9)$ \\
\hline$>1 \mathrm{yr}$ & $39(24.5)$ \\
\hline
\end{tabular}

Missing data was due to incomplete responses and unanswered questions. *Data presented as number, as some patients reported > 1 diagnosis. ITE: Institute of Technical Education

difference in the mean scores for knowledge between men and women (women $38.2 \%$, men $37.2 \%$; $p=0.56$ ). There was no association between age and global TOPICOP score (correlation coefficient $0.152 ; p=0.057$ ).

A significant proportion of respondents reported preferring non-steroidal alternatives, even if they were traditional alternative medications $(29.8 \%$ 'strongly agreed' or 'agreed') or more expensive $(49.1 \%$ 'strongly agreed' or 'agreed'). A majority of patients who used steroids believed that they benefitted from them $(71.9 \%$ 'agreed', $16.3 \%$ 'strongly agreed'). However, some reported experiencing side effects (21.6\% 'agreed', 5.2\% 'strongly agreed'). Patients with a longer period of steroid use (more than two weeks) were more likely to report having side effects than those with a short period of steroid use (longer use $33.3 \%$, shorter 
Table II. Questionnaire components on degree of steroid phobia.

\begin{tabular}{|c|c|c|c|c|c|c|}
\hline \multirow[t]{2}{*}{ Dimension } & \multirow[t]{2}{*}{ Domain subscore } & \multirow[t]{2}{*}{ Question } & \multicolumn{4}{|c|}{$\%$} \\
\hline & & & $\begin{array}{l}\text { Totally } \\
\text { disagree/never }\end{array}$ & $\begin{array}{l}\text { Not really agree/ } \\
\text { sometimes }\end{array}$ & $\begin{array}{l}\text { Almost } \\
\text { agree/often }\end{array}$ & $\begin{array}{l}\text { Totally } \\
\text { agree/always }\end{array}$ \\
\hline \multirow[t]{6}{*}{$\begin{array}{l}\text { Knowledge } \\
\text { and beliefs }\end{array}$} & \multirow{6}{*}{$\begin{array}{l}\text { Median 38.9\% } \\
\text { (IQR 27.8\%-50.0\%, } \\
\text { SD 24.4\%) }\end{array}$} & $\begin{array}{l}\text { TCS pass into the } \\
\text { bloodstream }\end{array}$ & 15.7 & 36.0 & 33.1 & 15.2 \\
\hline & & TCS can lead to infections & 29.6 & 54.8 & 10.2 & 1.1 \\
\hline & & TCS make you fat & 42.8 & 41.7 & 11.7 & 3.9 \\
\hline & & TCS damage your skin & 13.7 & 34.6 & 37.9 & 13.7 \\
\hline & & $\begin{array}{l}\text { TCS will affect my future } \\
\text { health }\end{array}$ & 12.4 & 41.2 & 33.3 & 13.0 \\
\hline & & TCS can lead to asthma & 37.6 & 56.2 & 5.1 & 1.1 \\
\hline \multirow[t]{3}{*}{ Fears } & \multirow[t]{3}{*}{$\begin{array}{l}\text { Median 44.4\% (IQR } \\
33.3 \%-66.7 \% \text {, SD 24.4\%) }\end{array}$} & $\begin{array}{l}\text { I am afraid of putting } \\
\text { cream (TCS) on certain zones } \\
\text { like the eyelids where the skin } \\
\text { is thinner }\end{array}$ & 11.4 & 30.8 & 27.6 & 30.3 \\
\hline & & $\begin{array}{l}\text { I don't know of any side } \\
\text { effects but I'm still afraid of } \\
\text { TCS }\end{array}$ & 25.1 & 39.1 & 29.1 & 6.7 \\
\hline & & $\begin{array}{l}\text { I am afraid of applying too } \\
\text { much cream (TCS) }\end{array}$ & 18.8 & 40.3 & 26.9 & 14.0 \\
\hline \multirow[t]{3}{*}{ Behaviour } & \multirow[t]{3}{*}{$\begin{array}{l}\text { Median 55.6\% (IQR } \\
33.3 \%-66.7 \% \text {, SD 27.2\%) }\end{array}$} & $\begin{array}{l}\text { I wait as long as I can before } \\
\text { treating myself with TCS }\end{array}$ & 18.8 & 43.8 & 24.3 & 13.0 \\
\hline & & $\begin{array}{l}\text { I stop treatment as soon as } \\
\text { I can }\end{array}$ & 11.4 & 30.4 & 33.7 & 24.5 \\
\hline & & I need reassurance about TCS & 17.9 & 35.3 & 25.0 & 21.7 \\
\hline $\begin{array}{l}\text { Global } \\
\text { TOPICOP } \\
\text { score }\end{array}$ & $\begin{array}{l}\text { Median 44.4\% (IQR } \\
33.3 \%-55.6 \% \text {, SD 17.6\%) }\end{array}$ & & & & & \\
\hline \multirow{5}{*}{$\begin{array}{l}\text { Additional } \\
\text { questions }\end{array}$} & & TCS can be addictive & 33.5 & 38.5 & 22.9 & 5.0 \\
\hline & & $\begin{array}{l}\text { I would rather try TCMs/ } \\
\text { herbal medications before } \\
\text { using TCS }\end{array}$ & 32.0 & 38.2 & 21.9 & 7.9 \\
\hline & & $\begin{array}{l}\text { I would rather use something } \\
\text { that does not contain steroids } \\
\text { even if it is more expensive }\end{array}$ & 13.3 & 37.6 & 30.9 & 18.2 \\
\hline & \multirow{2}{*}{$\begin{array}{l}\text { Of those who have used } \\
\text { steroids }\end{array}$} & I have benefited from TCS use & 3.1 & 8.8 & 71.9 & 16.3 \\
\hline & & $\begin{array}{l}\text { I have experienced side } \\
\text { effects from TCS use }\end{array}$ & 16.3 & 56.9 & 21.6 & 5.2 \\
\hline
\end{tabular}

IQR: interquartile range; SD: standard deviation; TCM: Traditional Chinese Medicine; TCS: topical corticosteroids; TOPICOP: Topical Corticosteroid Phobia

use $16.1 \% ; p=0.02)$. Dermatologists were the most common source of information, followed by the Internet and media, other doctors, and friends and family (Table III).

Trust was greatest in dermatologists, followed by other doctors, and lowest for friends/family and the Internet. The perceived underplay/exaggeration of risks was greater in the case of friends/family and the Internet and media, with a higher proportion of patients reporting underplayed risks or exaggerated risks from these above groups when compared to doctors.

\section{DISCUSSION}

Steroid phobia is prevalent and may limit efficacy of care due to reduced compliance. There has been significant variability in the reporting and quantification of TCS phobia. ${ }^{(2)}$ However, with the TOPICOP scale being developed recently, standardisation and comparisons across different groups are now possible.

Although the TOPICOP scale was designed for the assessment of steroid phobia in patients with atopic dermatitis, in our study, we included patients with other dermatological conditions as well as those who did not use steroids to assess steroid phobia in a larger and more diverse population. To our knowledge, this is the first study from Singapore to assess and quantify TCS phobia in the local population.

In our study, with a median global TOPICOP score of $44.4 \%$, findings would have placed our cohort approximately midway in terms of steroid phobia when compared to data from 15 other countries. ${ }^{(4)}$ However, the fact that our cohort included nonatopic dermatitis patients limited a direct comparison between our findings and those in the literature. 
Table III. Sources of information regarding topical steroids and level of trust.

$\%$

1. Where do you get information on TCS/steroid cream?

\begin{tabular}{|c|c|c|c|c|}
\hline & Never & Sometimes & Often & Always \\
\hline Dermatologists & 8.7 & 33.3 & 30.6 & 27.3 \\
\hline Other doctors & 16.0 & 46.9 & 23.4 & 13.7 \\
\hline Friends and family & 36.5 & 39.3 & 18.5 & 5.6 \\
\hline Internet and the media & 25.0 & 34.1 & 25.0 & 15.9 \\
\hline
\end{tabular}

2. How much do you trust the following sources for information on TCS?

\begin{tabular}{|c|c|c|c|c|}
\hline & Always distrust & Sometimes distrust & Sometimes trust & Always trust \\
\hline Dermatologists & 1.1 & 4.9 & 27.5 & 66.5 \\
\hline Other doctors & 1.7 & 10.7 & 52.5 & 35.0 \\
\hline Friends and family & 12.6 & 35.6 & 50.0 & 1.7 \\
\hline Internet and the media & 10.6 & 38.5 & 49.2 & 1.7 \\
\hline \multicolumn{5}{|c|}{ 3. How do you feel each source of information portrays the risks of TCS? } \\
\hline Dermatologists & 6.9 & 57.2 & 32.4 & 3.5 \\
\hline Other doctors & 6.0 & 60.2 & 31.9 & 1.8 \\
\hline Friends and family & 9.6 & 26.3 & 47.2 & 16.2 \\
\hline Internet and the media & 9.5 & 24.9 & 53.3 & 12.4 \\
\hline
\end{tabular}

TCS: topical corticosteroids

We initially postulated that patients who had received TCS might have lower TOPICOP scores than those who had not received TCS, perhaps on account of the greater awareness and knowledge of the treatment they required. However, this was not seen in our study. An interesting observation was that among participants who used short-term steroids (duration $<2$ weeks), $16.1 \%$ reported experiencing side effects. We postulate that these findings were in lieu of deterioration or changes in skin condition being wrongly attributed to be side effects of steroid creams, as true side effects are unlikely to develop during a short period of use. This suggested that more could be done to improve knowledge of steroids and their side effects through patient counselling and education.

Of note, a previous study by Huynh et al at our clinic in 2015 noted that the proportion of patients who stopped applying TCS upon subjective improvement was higher among those with higher educational qualification (secondary school education or above). ${ }^{(11)}$ This association was not evident in our study.

Studies ${ }^{(12,13)}$ have found that parents of girls had a higher TOPICOP score, while another study ${ }^{(5)}$ found that mothers had higher TOPICOP scores. A study of adults and children with various skin conditions also found that female participants had greater steroid phobia. ${ }^{(14)}$ The results of our present study also showed that female participants had higher TOPICOP scores. Rather than an actual knowledge gap, this gender difference in TCS phobia may be attributable to women being more cautious towards products that are applied to their skin and having greater concerns regarding their possible cutaneous side effects. Support for this hypothesis was found in the comparable knowledge subscores seen for men and women, which were in contrast to the higher fear and behaviour subscores seen for our women participants. Differences in mainstream media and information sources perused by women and men could also play a role in shaping behaviour and fears between the genders. This supports a more personalised and targeted approach, and has implications for the way patients are counselled.

Systematic reviews of Chinese herbal medicine for atopic dermatitis are inconclusive in terms of efficacy but have found that they are generally well tolerated. ${ }^{(15,16)}$ Given that a proportion of respondents reported a preference for traditional medications when compared to topical steroids, improved knowledge about these alternative therapies among dermatologists would help them better counsel such patients, especially those with steroid phobia. Discussion of topical non-steroidal immunomodulators, such as tacrolimus and pimecrolimus, earlier in the treatment course would empower patients to play an active role in managing their skin disease, given that we found that close to $50 \%$ of participants would rather use a non-steroidal agent even if it were more expensive.

Previous studies have cited general practitioners ${ }^{(17)}$ as the most common source of information for patients. In our population, the majority of information obtained was from dermatologists, followed by the Internet and media, and other doctors. However, trust was reportedly the highest in dermatologists and doctors when compared to other sources. This suggested that educational products and media should be closely tied to dermatologists, other doctors and traditional clinical consultants for greater effectiveness. Although we cannot control or prevent misrepresentation of steroids on the Internet, interventions to direct patients to online resources with balanced viewpoints and accurate medical information may help to mitigate the sensationalisation of steroid side effects while providing knowledge on appropriate and optimal steroid use. 
While steroid phobia is a negative concept, indiscriminate use of potent steroids may lead to side effects. A study by Charman and Williams ${ }^{(1)}$ found that $31 \%$ of patients who used hydrocortisone or betamethasone valerate had incorrectly graded the potency. Similarly, $37.5 \%$ of patients who had used both hydrocortisone and Dermovate ${ }^{\circledR}$ wrongly graded hydrocortisone as stronger or of equal potency as Dermovate. This highlights that patient education should not simply be focused on assuring patients of the safety of TCS but also target the varying potency of different formulations to minimise underuse of mild potency steroids and overuse of potent steroids.

Our study had limitations. We were unable to avoid selection bias, as the questionnaire was administered only in English, and this may limit the generalisability of our findings to the general population in Singapore. The English-illiterate or Mandarin only-speaking populations, who make up a majority of the older Singapore population, were not represented among our participants. This group, with different backgrounds and sources of knowledge, would be worth capturing in future studies. Furthermore, as this was a self-administered questionnaire, limitations of missing data and potential misinterpretation of questions by participants were present. Further studies correlating disease activity and compliance to steroid phobia may be beneficial.

In conclusion, we found that the prevalence of steroid phobia in our dermatology outpatient setting was moderately high, with women being associated with higher TOPICOP scores. Gender differences exist for TCS phobia. Misconceptions regarding the side effects of steroids were also common. Dermatologists were the most common source of information on TCS, and it was heartening to note that trust was also highest in dermatologists. Attempts and strategies to educate patients on TCS should take into account these factors.

\section{REFERENCES}

1. Charman $\mathrm{C}$, Williams $\mathrm{H}$. The use of corticosteroids and corticosteroid phobia in atopic dermatitis. Clin Dermatol 2003; 21:193-200.

2. Li AW, Yin ES, Antaya RJ. Topical corticosteroid phobia in atopic dermatitis: a systematic review. JAMA Dermatol 2017; 153:1036-42.

3. Moret L, Anthoine E, Aubert-Wastiaux H, et al. TOPICOPO: a new scale evaluating topical corticosteroid phobia among atopic dermatitis outpatients and their parents. PLoS One 2013; 8:e76493.

4. Stalder JF, Aubert H, Anthoine E, et al. Topical corticosteroid phobia in atopic dermatitis: international feasibility study of the TOPICOP score. Allergy 2017; 72:1713-9.

5. Moawad S, Mahé E, Aubert-Wastiaux H, et al. Topical corticosteroid concerns among parents of children with psoriasis versus atopic dermatitis: a French multicenter cross-sectional study. Am J Clin Dermatol 2018; 19:261-5.

6. Smith SD, Farrugia LL, Harris V, et al. Evaluation of the influence of family and friends, and the Internet on patient perceptions of long-term topical corticosteroid use. J Dermatol Treat 2017; 28:642-6.

7. Smith SD, Lee A, Blaszczynski A, Fischer G. Pharmacists' knowledge about use of topical corticosteroids in atopic dermatitis: pre and post continuing professional development education. Australas J Dermatol 2016; 57:199-204.

8. Farrugia LL, Lee A, Fischer G, et al. Evaluation of the influence of pharmacists and GPs on patient perceptions of long-term topical corticosteroid use. J Dermatol Treat 2017; 28:112-8

9. Lee JY, Her Y, Kim CW, Kim SS. Topical corticosteroid phobia among parents of children with atopic eczema in Korea. Ann Dermatol 2015; 27:499-506.

10. Hon KL, Tsang YC, Pong NH, et al. Correlations among steroid fear, acceptability, usage frequency, quality of life and disease severity in childhood eczema. J Dermatolog Treat 2015; 26:418-25.

11. Huynh RK, Wong HH, Aw D, Toh MP. Adherence to topical corticosteroids and moisturisers in adults with endogenous eczema in Singapore. Hong Kong J Dermatol Venereol 2015; 23:161-74

12. Gonzales F, Ramdane N, Delebarre-Sauvage C, et al. Monitoring of topical corticosteroid phobia in a population of parents with children with atopic dermatitis using the TOPICOP® scale: prevalence, risk factors and the impact of therapeutic patient education. J Eur Acad Dermatol Venereol 2017; 31:e172-4.

13. Kojima R, Fujiwara T, Matsuda A, et al. Factors associated with steroid phobia in caregivers of children with atopic dermatitis. Pediatr Dermatol 2013; 30:29-35.

14. Müller SM, Tomaschett D, Euler S, et al. Topical corticosteroid concerns in dermatological outpatients: a cross-sectional and interventional study. Dermatology 2016; 232:444-52.

15. Gu S, Yang AW, Xue CC, et al. Chinese herbal medicine for atopic eczema. Cochrane Database Syst Rev 2013; (9):CD008642.

16. Gu SX, Zhang AL, Coyle ME, Chen D, Xue CC. Chinese herbal medicine for atopic eczema: an overview of clinical evidence. J Dermatolog Treat 2017; 28:246-50

17. Charman CR, Morris AD, Williams HC. Topical corticosteroid phobia in patients with atopic eczema. Br J Dermatol 2000; 142:931-6. 